\title{
Metallurgical alterations in the surface of steel cavities machined by EDM
}

\author{
Rodrigo Panosso Zeilmann, Thiago Vacaro, \\ Fernando Moreira Zanotto, Mariana Czarnobay
}

Universidade de Caxias do Sul, Centro de Ciências Exatas e Tecnologia, Programa de Pós-Graduação em Engenharia Mecânica, Rua Francisco Getúlio Vargas, 1130, 95001-970, Caxias do Sul, RS.

E-mail: rpzeilma@ucs.br; tvacaro@ucs.br; fmbordin@ucs.com.br; mczanotto@ucs.br

\begin{abstract}
The electrical discharge machining (EDM) is a process characterized by high thermal demands, which tend to cause metallurgical changes in the surface of the workpiece [1-2]. This work aims to conduct a discussion of metallurgical changes in the surface of cavities obtained by the process of EDM in the machining of steel. Several variables were employed, such as cavity depth, electrode geometry and technological parameters of the process. Thus, the goal was to identify the different metallurgical changes that can occur in the machined surfaces. The evaluation of these changes was made from metallographic analysis, measurements of microhardness and of the depth of the layer affected by process. The results of this work identified several metallurgical changes such as formation of white layer, hardness variation and change of microstructure. The occurrence of microcracks also was observed, especially in severe conditions. The greatest variations in results were caused by the change of technological parameters. However, the variation in cavity depth and the change of the electrode geometry also showed influence on the results.
\end{abstract}

Keywords: machining, electrical discharge machining, surface quality.

\section{INTRODUCTION}

Electrical Discharge Machining (EDM) is one of the most known and studied unconventional machining process. The main principle of processing the material is to copy the form of the work tool into the workpiece. Apparently it is a very simple process, but it involves many phenomena during the machining [1]. EDM is a process for eroding and removing material from electrically conductive materials by use of consecutive electric sparks. The process is carried out in a dielectric liquid with a small gap between the workpiece and the electrode. Each electrical discharge generates heat energy in a narrow area that locally melts, evaporates and even ionizes workpiece material. Some of the melted and all of the evaporated material is then quenched and flushed away by dielectric liquid and the remaining melt recast on the finished surface. The recast layer is referred as white layer since it is difficult to etch and its appearance under optical microscope is white. Beneath the recast layer, a heat affected zone is formed due to the rapid heating and quenching cycles during the process [2]].

EDM has a number advantages, including a non-contact machining operation, the ability to machine thin plates without causing distortion, the ability to produce fine arrays of micro-holes with high depth-towidth aspect ratios, etc. [3] . EDM also provides significant improvement in productivity and extends the range and sophistication of tools and dies that can be produced [4]. EDM is widely used for manufacturing of mechanical components made on hard metals such as high alloys, High-Speed-Steels and refract alloys []ㅡ. But the application area of EDM is not limited by the hardness or strength of material to be machined. It can be used to machine any conductive material. Since there is no mechanical contact between the electrode and the work material, it is possible to machine complex geometries with high slenderness ratios by using thin electrodes [4]. The absence of direct contact between the tool and the electrode also avoid process problems such as mechanical stresses and vibrations caused by conventional machining processes [ $[\underline{6}$.

The EDM process has special applications in the aeronautical and automotive industries. In this context, the machined surface integrity of work-materials is of prime concern [7]. The surface integrity of electric-discharge machined parts is characterized by the surface roughness, the presence of white layer, surface crack formations, the metallurgical alterations on the surface and under surface regions, hardness distribution, etc. [8]. There are many process variables that affect the surface integrity such as pulse duration, peak current, open gap voltage, electrode polarity, material properties of the tool electrode, workpiece and dielectric liquid, debris concentration and even size of the electrode. These effects impacts on mechanical properties of the material such as fatigue strength, hardness corrosion and wear resistance [2]. Surface 
morphology also plays an important part in understanding the characteristics of machined surfaces. The surface morphology of parts machined by EDM is a function of two parameters, pulsed current and pulse-on duration, both of which are settings of the power supply [9].

High thermal effects generated during the material removal by EDM induce mechanical, metallurgical and chemical modifications at the upper layers of the machined surfaces. These layers are characterized by high work hardening, high tensile residual stresses and wide thermal crack networks that have detrimental effects on the fatigue life of the machined components [5]. Small surface defects induced by EDM have been known to reduce both fracture toughness and fatigue strength of certain materials, depending on the properties of the surface and near-surface regions [10]. EDM machined components are commonly applied in high-temperature, high-stress, and high-fatigue-load environments. Under such conditions, the cracks on the machined surface act as stress raisers and lead to a considerable reduction on the fatigue life of the component. Although a post-machining treatment can be performed to remove the recast layer to ensure the mechanical integrity of the component, this adds to the time and expense of the manufacturing operation [3].

As stated above, the metallurgical alterations generated by EDM process cause changes of physical and chemical properties on the workpiece surface, which has significant influence in the performance of machined parts in service and tend to increase the manufacturing costs. Therefore, it is important to identify the characteristics and extent of these metallurgical alterations. This work presents a discussion of the main alterations observed in the surface of steel cavities machined by EDM and how they are influenced by some variables of the process.

\section{METHODOLOGY}

The experiments were performed on an Engemaq machine, EDM $440 \mathrm{NC}$ model. The tool was a copper electrode, with dimensions of 10 per $10 \mathrm{~mm}$ (for square cavities) and diameter of $12 \mathrm{~mm}$ (for cylindrical cavities).

The dielectric fluid was an integral oil, Microcorte 102-A model, produced by Micro Química Ltda.

In the experiments cylindrical and square cavities were machined. As workpiece, ABNT 1045 steel was used in the machining of cylindrical cavities and ABNT P20 steel with hardness between 36 and 38 HRc was used for square cavities. The dimensions of cylindrical cavities were the diameter of $12 \mathrm{~mm}$ and depth of $8 \mathrm{~mm}$. For square cavities the dimensions were 10 per10 $\mathrm{mm}$ and depth of 3 and $9 \mathrm{~mm}$. Initially, a preroughing operation was performed on all square cavities, leaving an excess metal layer of $0.3 \mathrm{~mm}$ because preliminary tests showed an affected layer by roughing of approximately $0.1 \mathrm{~mm}$. Before removing the excess metal layer of each cavity, the electrode was machined in order to minimize the influence of electrode wear on the test results. Two different geometries were used on the square electrodes, with (radius was 1 $\mathrm{mm})$ and without radius on the edges.

Three EDM operations were performed by finishing, intermediate and roughing conditions. Table 1 shows the values of technological parameters used in the experiments. For each experiment condition was carried out two experiments.

Table 1: Technological parameters used in the experiments.

\begin{tabular}{c|c|c|c|c}
\hline Machining condition & I [A] & TON [ $\boldsymbol{\mu s}]$ & DT [\%] & $\begin{array}{c}\text { Open GAP } \\
\text { voltage [V] }\end{array}$ \\
\hline Finishing & 1.5 & 20 & 35 & 6 \\
Intermediate & 6 & 100 & 55 & 5 \\
Roughing & 36 & 300 & 75 & 4 \\
\hline
\end{tabular}

The process occurred in cycles of 3 seconds of intermittent erosion, with a retreat of $1 \mathrm{~mm}$ per cycle and full retreat out of the cavity every 10 complete cycles. The machining occurred with immersion of the workpiece in dielectric and side flow directly into the cavity with pressure of $0.5 \mathrm{kgf} / \mathrm{cm}^{2}$.

A Nikon optical microscope was used for metallographic analysis and microhardness measurements were performed with a Shimadzu hardness tester, HMV-2 model. cavities.

The presence of microcracks was only qualitatively observed, for both square and cylindrical 


\section{SURFACE ALTERATIONS PRODUCED BY EDM}

\subsection{Surface topography}

The distinctive morphology of a surface which has undergone EDM machining is due to the enormous amount of heat generated by the discharges, which causes melting and vaporization of the material, followed by rapid cooling. The surface topography of the final region of cylindrical cavities presented in Figure 1, which also presents roughness results, reveals that the surface roughness is caused by an uneven fusing structure, globules of debris, shallow craters, pockmarks, voids and cracks. These effects become more pronounced as the pulse current and pulse-on duration increase. The EDM is characterized by the use of high local voltages and temperatures, which cause erosion and vaporization of the material. The surface roughness is influenced by the size, appearance and depth of the electrode discharge [11].

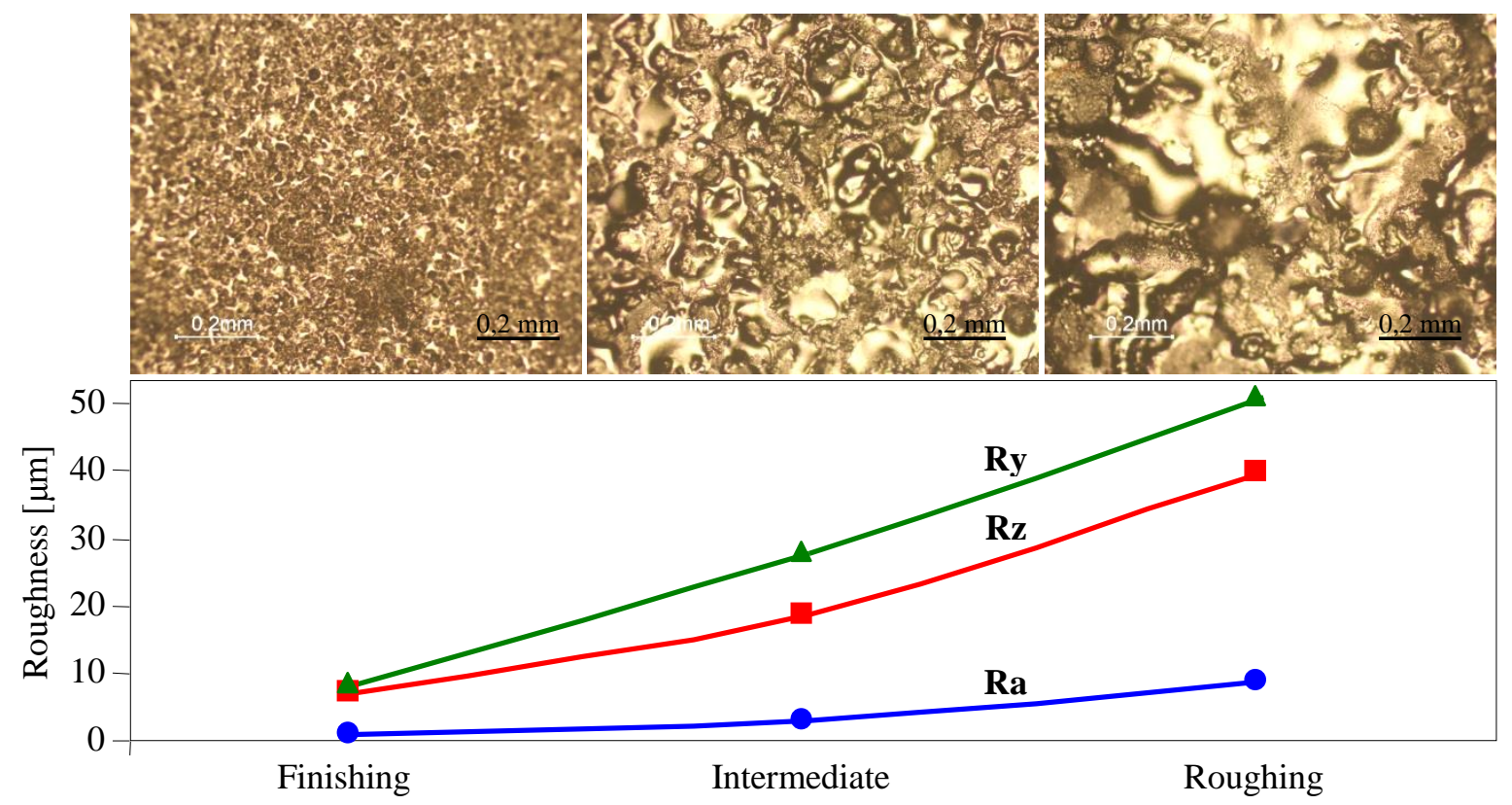

Figure 1: Effects of the different parameters on the surface roughness and texture.

With each discharge, a crater is formed on the workpiece and a smaller crater is formed on the tool electrode. Of the molten material produced by the discharge, only $15 \%$ or less is carried away by the dielectric fluid. The remaining melt solidifies to form an undulating terrain. The pockmarks which can be observed on surfaces are formed by entrapped gases escaping from the deposited material [12].

The applied current on the surface is increased as the machining conditions are changed from finishing to roughing parameters. This implies in greater heat generation and increase on the melting and evaporation of material, which results in deeper craters on the surface, as can be observed in texture images of Figure 1.

The surface roughness also increases when discharge current increases. When discharge current occurs between tool and workpiece, both surfaces melt and vaporize. At the same time, the dielectric fluid also vapors and inflates, resulting in high gas pressure and impacts the workpiece surface. When some materials on the surface of the workpiece was removed by discharge spark, craters occur. If discharge current increases, the material remove ratio also increases, but it produces large craters and obtains large surface roughness [13].The peculiarity of an electrical discharge machined surface is determined by various factors associated with a complex erosion mechanism. Randomly overlapping craters of dimensions varying with pulse energy cover the machined surface, their sizes and positions reflecting the stochastic nature of the process [14].

\subsection{Affected layers}

For EDM surfaces, the temperature gradient created by the electrical sparks generates a gradient of microstructure. This microstructure gradient is characterized by three layers, Figure 2:

- the first layer is a brittle white layer that has a dendritic structure and a high hardness (HV 100 gf > 800);

- $\quad$ the second layer is a martensitic quenched layer with hardness HV $100 \mathrm{gf} \leq 800$; and 
- the third layer is a transition layer that is followed by the bulk material [5].

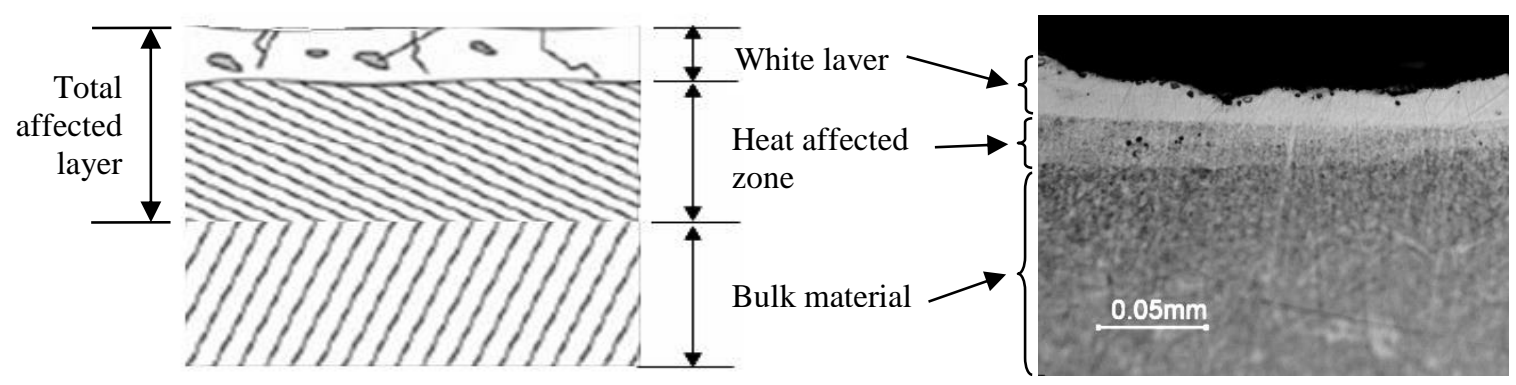

Figure2: Characteristic layers of a subsurface.

The first is a recast layer, usually referred to as the white layer due to its resistance to etching on ferrous material. This layer is composed of several microscopic metallurgical layers, and its composition is dependent on the machining conditions [4]. The white layer is heavily alloyed with the pyrolysis products from the cracked dielectric liquid as well as tool electrode and has high hardness values. The solidification of the molten metal takes place simultaneously both from surface and base material during machining [2].

The white layer is composed mainly of martensite and retained austenite, with some dissolved carbide. This layer is so densely infiltrated with carbon that it has a separate, distinct structure, totally distinguishable from the parent material. Carbon enrichment of the white layer also leads to high hardness. The white layer thickness is mainly influenced by the pulse-on duration, and that it increases as the pulse-on duration increases. This is explained by the fact that the amount of molten metal which can be flushed away by the dielectric is a constant percentage. Therefore, as more heat is transferred into the sample as the pulse-on duration increases, the dielectric is increasingly unable to clear away the molten material, and so it builds up upon the surface of the sample. During the subsequent cooling, this molten material solidifies to form the white layer, the depth of which depends upon the volume of molten material rate when the pulse current is high. When the EDM surface undulates dramatically, there is significant variation of the white layer thickness [11]. According to Casas et al. [15], the presence of this layer causes the reduction of the fracture toughness and fatigue resistance.

The intermediate layer is a heat-affected zone, where the heat is not high enough to cause melting, but is sufficiently high to induce micro-structural transformation in the material [12]. The depth of the recast layer and the heat-affected zone is determined by the heat sinking ability of the material and the power used for the cut. This altered metal zone influences the quality of the surface integrity. Automatic finishing circuits available on CNC machines greatly reduce the recast layer, but do not eliminate the heat-affected zone [16].

Lee and Tai [11] conducted EDM experiments of D2 and H13 tool steels. They concluded that white layer thickness increases as peak current and pulse-on duration increase. Of these two parameters, they observed that the influence of pulse-on duration was more significant. The study of Lee and Li [14] showed similar results, on the EDM of a tungsten carbide. Boujelbene et al. [17] observed that increasing the energy discharge increases the instability of the process and the white layer increases. According to the authors, with the increase of the discharge energy, the number of particles in the gap becomes very large and these particles can form electrically conducting paths between the tool electrode and the workpiece. The particles cause unwanted discharges, which become electric arcs that damage the electrode surfaces (tool and workpiece surfaces), leading to the occurrence of microcracks. According to Guu et al. [1] a good surface finishing can be obtained through EDM process by setting the machine parameters at low pulse energy. This condition reduces the frequency of bursts of dielectric fluid and melt expulsions, resulting in lesser damage to the surface.

Figure 3 shows the graphs of the total affected layer and microhardness profiles of the final regions of cylindrical cavities. The roughing condition, a process of faster material removal, uses greater parameters than the finishing condition, and thus, generates higher temperature at the machined cavity, causing the appearance of a thicker white layer, as well as the heat-affected zone. The heat is very intense and generated as the result of each discharge, causing high temperature gradients, which with rapid cooling, provides hardness increase [10]. This increase of hardness can be observed in the graphs of Figure 3, especially for intermediate and roughing conditions. It was not possible to observe the variation of hardness in finishing condition because the distance from the first indentation of the microhardness test is greater than the maximum thickness of the affected layer. 

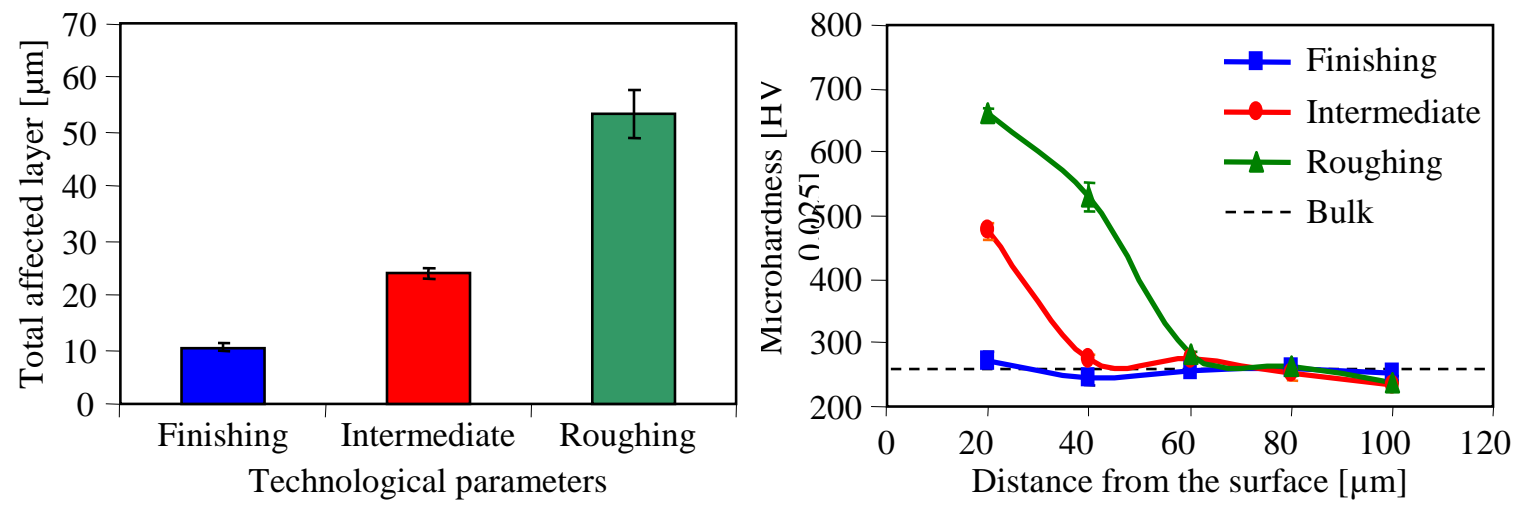

Figure 3: Graphs of total affected layer and microhardness profiles of the final regions of cylindrical cavities.

Figure 4 shows the microhardness profile from the bottom of the square cavities machined with electrodes with and without radius, roughing parameters and depths of 3 and $9 \mathrm{~mm}$. The figure also shows metallographic pictures of each tested condition.

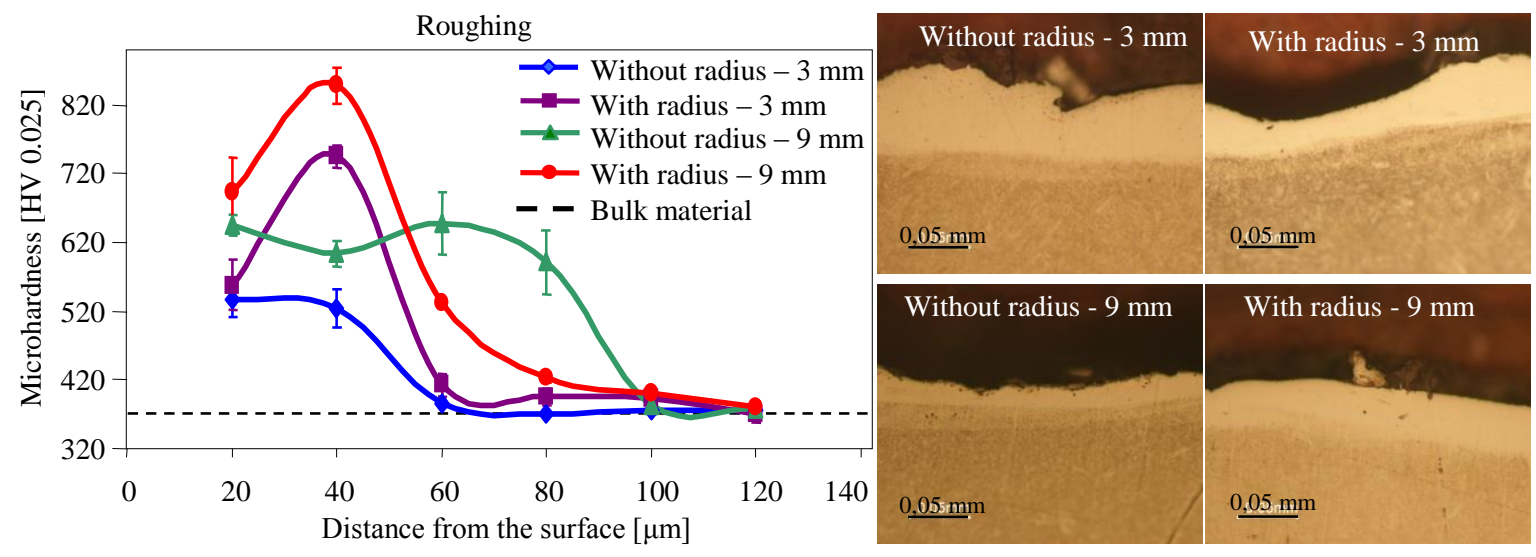

Figure 4: Microhardness profiles and metallographic images from the bottom of square cavities machined

with roughing parameters.

As results there are variations in the hardness values. Considering the same geometry of the electrode, with the increase in the depth of the cavity there is an increase in the hardness values. The same behavior occurs when comparing conditions with and without radius on the electrode, which has greater hardness values for cavities machined with electrodes with radius. A possible explanation is that the radius may have caused a better cleaning flow by the dielectric fluid. According to Chiaverini [19], the circulation of the oil causes a better contact of the workpiece surface and the cooling environment (the dielectric fluid), promoting a quicker cooling, consequently, a greater surface hardness. This occurs because when the flow lines of the fluid encounter regions of abrupt change of direction, such as corners, stagnant and rotational zones may appear, characterizing vortex zones, which difficult the flow of the fluid [20].

\subsection{Microcracks}

Components machined by EDM, such as tools and dies, are often subjected to severe cyclic pressure and temperature loadings. Hence, the surface defects, particularly cracks, may reduce the material resistance to fatigue and corrosion, especially under tensile loading conditions. Therefore, surface cracks became a fundamental consideration when evaluating the performance of the EDM technique and the prime objective of EDM must be to establish the conditions that suppress their formation [4]. If these defects are not avoided, the EDM surface needs to be subjected to EDM processes such as grinding and polishing to remove these subsurface defects. These machining treatments significantly contribute to the rising cost and machining time [7].

Figure 5 shows the appearance of microcracks in the white layer, on the bottom of square cavities machined with roughing parameters, for depths of $3 \mathrm{~mm}$ (electrode with radius) and $9 \mathrm{~mm}$ (electrode without radius). 

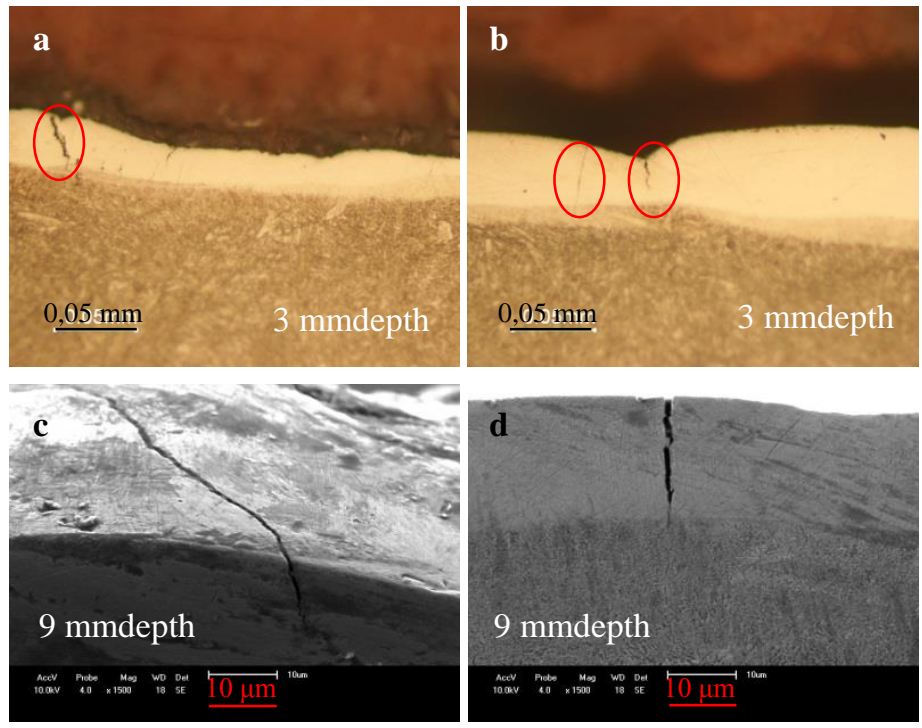

Figure 5: Metallographic (a, b) and SEM (c, d) images of microcracks found for the roughing process.

The appearance of microcracks in the EDM process are usually white layer sized and propagate in the vertical direction, perpendicular to the analyzed surface. The Figure 5 (c) presents the micro-crack on the material's border, for square cavities. The crack, for the purpose of this study, was only qualitatively observed. For cylindrical cavities, the presence of cracks was also detected.

The formation of cracks is attributed to the differentials of high contraction stresses exceeding the material's ultimate tensile stress within the white layer [2]. Thermal stress is produced when the electrode discharges bombard the surface of the sample during the machining process. Tensile stress within the sample is generated because not all of the material which melts during the machining process is swept away from the component's surface by the dielectric. Due to the ingress of carbon, the melted material contracts more than the unaffected parent part during the cooling process, and when the stress in the surface exceeds the material's ultimate tensile strength, cracks are formed [11]. The existence of crack networks in a field of tensile residual stresses is the main reason of their instability regarding the coalescence and propagation of these cracks under cyclic loading [5].

Surface cracks have three distinctive characteristics. The first type of microcracks, called surface cracks, exists in the white layer, initiating at its surface and traveling down perpendicularly toward the deferential zone, separating the heat-affected zone and the white layer, and usually terminates at this interference. These cracks are observed when machining is performed in a hydrocarbon-based dielectric liquid with high pulse-on duration and low discharge current. The second type of microcracks, called penetrating cracks, penetrates the entire white layer thickness to an extent into the parent material and usually is observed when machining is performed in deionized water and work material is quenched or quenched and tempered prior to machining. On the other hand, the third type of microcracks is visualized usually around globular or irregularly shaped attachments on crater rims. Such cracks have very low penetration depth and are randomly distributed on the surface [4].

The characteristics of the recast layer are closely related to the phase transformation which takes place during the solidification process. This is dependent on the chemical composition of the original workpiece, the heat treatment conditions applied prior to machining and the EDM machining parameters, most notably the pulse current and the pulse-on duration. The depth and size of the cracks formed on the recast layer increase as the heat energy per spark increases [3] . Of all the factors which affect crack formation, thermal conductivity has the most significant influence since a material with a higher thermal conductivity has the ability to quickly conduct heat away from the heating region, thus reducing the tendency for cracks to form [11].

\section{CONCLUSION}

This paper presented a discussion of the main metallurgical alterations in surfaces machined by EDM process. These alterations can have significant influence on the mechanical properties of the surface and on the reliability and of the machined parts.

Several configurations of experiments were designed. The change of technological parameters caused the greater effects on the surfaces. Roughing parameters submit the surface to higher thermal loads, 
which lead to more significant metallurgical alterations than intermediate and finishing parameters. The surfaces machined with roughing parameters presented surface roughness five to eight times greater than the machined with finishing parameters. Similar results were obtained in affected layer analysis, which the results were approximately five times greater for roughing condition. The variation of the geometry of the electrode and of the cavities depth also influenced the results of surface changes, but in lesser magnitude. The hardness results for the surfaces machined with electrodes with radius were up to $40 \%$ greater in comparison to surfaces machined with electrodes without radius. Considering the variation of the cavities depth, the hardness was $25 \%$ higher for $9 \mathrm{~mm}$.

These results demonstrate the importance of identifying and understanding the formation mechanisms of these metallurgical alterations, in order to minimize their occurrence and provide a better quality for the EDM machined surfaces.

\section{ACKNOWLEDGEMENTS}

The authors would like to thanks the University of Caxias do Sul, for the support on the technical project and financial support.

\section{REFERENCES}

[1] POPA, M.S., CONTIU, G., POP, G., et al.,"New technologies and applications of EDM process",International Journal of Materials Forming, v. 2, n. 1, pp. 633-636, 2009.

[2] EKMEKCI, B.,"Residual stresses and white layer in electric discharge machining (EDM)",Applied Surface Science, v. 253, n.23, p. 9234-9240, 2007.

[3] TAI, T.Y., LU, S.J.,"Improving the fatigue life of electro-discharge-machined SDK11 tool steel via the suppression of surface cracks",International Journal of Fatigue, v. 31, n.3,pp. 433-438, 2009.

[4] EKMEKCI, B.,"White layer composition, heat treatment, and crack formation in electric discharge machining process",Metallurgical and Materials Transactions B, v. 40,n.1, pp. 70-81, 2009.

[5] GHANEM, F., FREDJ, N.B., SIDHOM, H., et al.,"Effects of finishing processes on the fatigue life improvements of electro-machined surfaces of tool steel",International Journal of Advanced Manufacturing Technology, v. 52, n.5-8, pp. 583-595, 2011.

[6] PELLICER, N., CIURANA, J., DELGADO, J.,"Tool electrode geometry and process parameters influence on different feature geometry and surface quality in electrical discharge machining of AISI H13 steel”,Journal of Intelligent Manufacturing, v. 22, n.4, pp. 575-584, 2011.

[7] KUMAR, P.D., "Study of thermal stresses induced surface damage under growing plasma channel in electro-discharge machining”,Journal of Materials Processing Technology, v. 202, n.1-3, pp. 86-95, 2008.

[8] HASÇALIK, A., ÇAYDAS, U.,"Electrical discharge machining of titanium alloy (Ti-6Al-4V)",Applied Surface Science, v. 253, n.22, pp. 9007-9016, 2007.

[9] GUU, Y.H., HOU, M.T.-K.,"Effect of machining parameters on surface textures in EDM of Fe-Mn-Al alloy”,Materials Science and Engineering A, v. 466, n.1-2,pp. 61-67, 2007.

[10] LAI, L.-C., CHIOU, W.-A., EARTHMAN, J.C.,"Influence of electrical discharged machining and surface defects on the fatigue strength of electrodeposited nanocrystalline Ni",International Journal of Fatigue, v. 32, n.3,pp. 584-591, 2010.

[11] LEE, H.T., TAI, T.Y., "Relationship between EDM parameters and surface crack formation”, Journal of Materials Processing Technology, v. 142,n.3, pp. 676-683, 2003.

[12] REBELO, J.C., MORAO, DIAS, A., KREMER, D., et al.,"Influence of EDM pulse energy on the surface integrity of martensitic steels”,Journal of Materials Processing Technology, v. 84, n.1-3, pp. 90-96, 1998. 
[13] CHEN, S.L., HSU, Q.C.,"Studies on electric-discharge machining of non-contact seal face grooves",Journal of Materials Processing Technology, v. 140, n.1-3, pp. 363-367, 2003.

[14] LEE, S.H., LI, X., "Study of the surface integrity of the machined workpiece in the EDM of tungsten carbide”, Journal of Materials Processing Technology, v. 139, n.1-3, pp. 315-321, 2003.

[15] CASAS, B., TORRES, Y., LLANES, L.,"Fracture and fatigue behavior of electrical-discharge machined cemented carbides",International Journal of Refractory Metals and Hard Materials, v. 24, n.1-2,pp. 162-167, 2006.

[16] KUMAR, S., SINGH, R., SINGH, T.P., et al., "Surface modification by electrical discharge machining: A review”, Journal of Materials Processing Technology, v. 209, n.8, pp. 3675-3687, 2009.

[17] BOUJELBENE, M., BAYRAKTAR, E., TEBNI, W., et al.,'Influence of machining parameters on the surface integrity in electrical discharge machining", Archives of Materials Science and Engineering, v.37, n.2, pp. 110-116, 2009.

[18] GUU, Y.H., HOCHENG, H., CHOU, C.Y., et al., "Effect of electrical discharge machining on surface characteristics and machining damage of AISI D2 tool steel", Materials Scienceand Engineering A, v. 358, n.1-2, pp. 37-43, 2003.

[19] CHIAVERINI, V.,Aços e ferros fundidos: características gerais, tratamentos térmicos, principais tipos,7 ed., São Paulo, ABM, 1996.

[20] MASSEY, B.S., Mechanics of fluids,6 ed., Lisboa, Foundation Calouste Gulbenkian, 2002. 